\title{
Gastrodin Suppresses the Amyloid $\beta$-Induced Increase of Spontaneous Discharge in the Entorhinal Cortex of Rats
}

\author{
Peng-zhi Chen, ${ }^{1}$ Hui-hui Jiang, ${ }^{1}$ Bo Wen, ${ }^{1}$ Shuan-cheng Ren, ${ }^{1}$ Yang Chen, ${ }^{2}$ Wei-gang Ji, \\ Bo Hu, ${ }^{1}$ Jun Zhang, ${ }^{1}$ Fenglian $\mathrm{Xu}^{,}{ }^{4}$ and Zhi-ru Zhu ${ }^{1}$ \\ ${ }^{1}$ Department of Physiology, Third Military Medical University, Chongqing 400038, China \\ ${ }^{2}$ School of Acupuncture and Tuina, Chengdu University of Traditional Chinese Medicine, Chengdu 611130, China \\ ${ }^{3}$ Department of Chemistry, Third Military Medical University, Chongqing 400038, China \\ ${ }^{4}$ Department of Physiology and Pharmacology, The Hotchkiss Brain Institute, Cumming School of Medicine, University of Calgary, \\ Calgary, Canada T2N 4N1
}

Correspondence should be addressed to Zhi-ru Zhu; zhuzr2013@163.com

Received 20 June 2014; Revised 31 August 2014; Accepted 1 September 2014; Published 30 October 2014

Academic Editor: Donald A. Wilson

Copyright (c) 2014 Peng-zhi Chen et al. This is an open access article distributed under the Creative Commons Attribution License, which permits unrestricted use, distribution, and reproduction in any medium, provided the original work is properly cited.

Accumulated soluble amyloid beta- (A $\beta$-) induced aberrant neuronal network activity may directly contribute to cognitive deficits, which are the most outstanding characteristics of Alzheimer's disease (AD). The entorhinal cortex (EC) is one of the earliest affected brain regions in $\mathrm{AD}$. Impairments of $\mathrm{EC}$ neurons are responsible for the cognitive deficits in $\mathrm{AD}$. However, little effort has been made to investigate the effects of soluble $\mathrm{A} \beta$ on the discharge properties of $\mathrm{EC}$ neurons in vivo. The present study was designed to examine the effects of soluble $\mathrm{A} \beta_{1-42}$ on the discharge properties of EC neurons, using in vivo extracellular single unit recordings. The protective effects of gastrodin (GAS) were also investigated against $\mathrm{A} \beta_{1-42}$-induced alterations in EC neuronal activities. The results showed that the spontaneous discharge of EC neurons was increased by local application of soluble A $\beta_{1-42}$ and that GAS can effectively reverse $\mathrm{A} \beta_{1-42}$-induced facilitation of spontaneous discharge in a concentration-dependent manner. Moreover, wholecell patch clamp results indicated that the protective function of GAS on abnormal hyperexcitability may be partially mediated by its inhibitory action on $\mathrm{A} \beta_{1-42}$-elicited inward currents in EC neurons. Our study suggested that GAS may provide neuroprotective effects on $\mathrm{A} \beta_{1-42}$-induced hyperactivity in EC neurons of rats.

\section{Introduction}

Alzheimer's disease (AD) is the most common but incurable neurodegenerative disorder and is known to contribute to dementia among the elderly. Amyloid beta $(\mathrm{A} \beta)$ peptide, derived from the amyloid precursor protein, is regarded as the pivotal toxicant of $\mathrm{AD}$ and causes a variety of neuropathological changes, such as synaptic loss, dysfunction of neuronal transmission, and neuronal death [1]. Recently, increasing evidence has suggested that $\mathrm{A} \beta$-induced perturbation of neuronal network activity may be a major and early contributor to $\mathrm{AD}$ pathogenesis. Aberrant neuronal network activity is observed in $\mathrm{AD}$ patients and transgenic mouse models of $\mathrm{AD}$, which is thought to induce dysfunction and memory deficits $[2,3]$.
The entorhinal-hippocampal network is a vital circuit in memory consolidation and recall [4], which is seriously affected during the progression of $\mathrm{AD}$ [3]. The entorhinal cortex (EC) has been proven to be one of the earliest brain regions impaired in $\mathrm{AD}$ [5]. Radiological studies have also provided evidence that early-stage AD patients exhibit structural and functional changes of the EC $[6,7]$. Previous studies suggested that elevated levels of $A \beta$, especially $A \beta_{1-42}$, which has been described as the most toxic variant of $A \beta$, altered the excitability of neurons in the rat hippocampus $[8,9]$. High levels of $A \beta_{1-42}$ promoted suprasynchronization between individual rat prefrontal cortical neurons by increasing their excitability [10]. In addition, it is reported that $\mathrm{A} \beta_{1-42}$ could disturb the patterns of spontaneous discharge in the hippocampal CA1 region of rats [11]. However, there is 


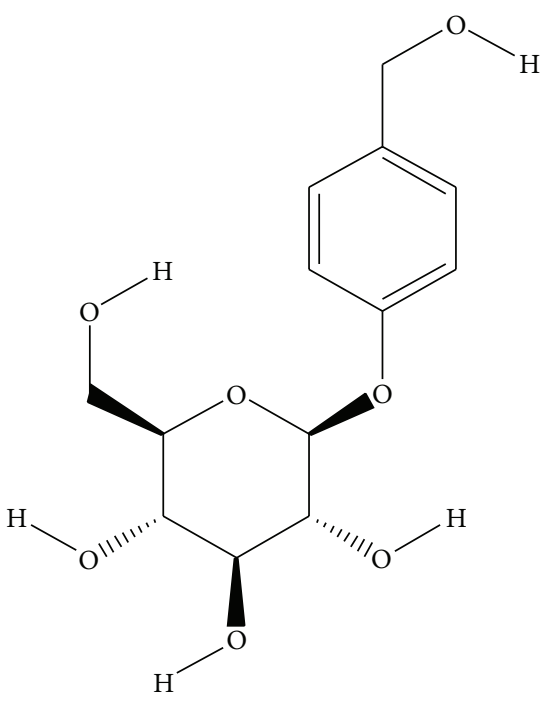

Figure 1: Structures of 4-hydroxybenzyl alcohol 4-O-beta-D-glucopyranoside (GAS).

little related electrophysiological data concerning EC neurons in the context of high level of $A \beta_{1-42}$.

Gastrodin (GAS) is a traditional Chinese medicine isolated from Gastrodia elata (Figure 1) and is regarded as one of the most important traditional medicines in Oriental countries. It is officially listed in the Chinese Pharmacopoeia and is used as an anticonvulsant, analgesic, and sedative against vertigo, general paralysis, epilepsy, and tetanus [12]. Modern clinical studies have demonstrated its efficiency as an antiepileptic drug [13] and its protective effects against cognitive decline in patients after cardiac surgery with cardiopulmonary bypass [14]. Furthermore, recent in vitro studies found that GAS had neuroprotective effects on the cellular model of $\mathrm{AD}$ induced by $\mathrm{A} \beta_{25-35}$ [15] and could facilitate learning and memory [16]. A recent study also demonstrated that $\mathrm{A} \beta_{1-42}$-related oxidative damage was decreased by GAS in primary cultured rat hippocampal neurons [17]. Despite these observations, whether GAS has neuroprotective effects against $\mathrm{A} \beta_{1-42}$-induced perturbation of neuronal network activity in vivo is unknown. Therefore, whether $A \beta_{1-42}$ could disturb the spike discharge of EC neurons in vivo and whether the $\mathrm{A} \beta_{1-42}$-disturbed spike discharge could be remolded by GAS are significant questions. In the present study, we used extracellular recording and whole-cell patch clamp recording to investigate the effects of GAS on EC aberrant firing patterns induced by the local application of soluble $\mathrm{A} \beta_{1-42}$.

\section{Materials and Methods}

2.1. Animals and Surgery. Male Sprague-Dawley rats (200$250 \mathrm{~g}$ ) were obtained from the Laboratory Animal Center at the Third Military Medical University in China. All protocols and procedures were approved by the University Animal Care and Use Committee. Animals were deeply anesthetized using urethane $(1.5 \mathrm{~g} / \mathrm{kg})$ before being placed in a stereotaxic apparatus. The skull was exposed, and a small hole was drilled to expose $\mathrm{EC}$ region (from bregma: $\mathrm{AP}-6.6 \mathrm{~mm}$ and $\mathrm{ML}$ $4.7 \mathrm{~mm}$; depth from skull surface: $6.8 \mathrm{~mm}$ ) [18].

2.2. Drugs. All reagents were obtained from (Sigma-Aldrich, USA) with the exception of scrambled $\mathrm{A} \beta_{1-42}$ peptide (Anaspec, Fremont, CA, USA). Soluble $A \beta_{1-42}$ was prepared as described previously [19]. In brief, $A \beta_{1-42}$ was first dissolved in hexafluoro-2-propanol (HFIP) and aliquoted. HFIP was then removed by evaporation under vacuum, and the resulting clear peptide films were stored at $-20^{\circ} \mathrm{C}$. Prior to use, an aliquot of $\mathrm{A} \beta_{1-42}$ peptide film was dissolved in anhydrous dimethyl sulfoxide (DMSO) and added to ice-cold artificial cerebral spinal fluid (ACSF) to obtain a working concentration of $200 \mu \mathrm{M}$. This solution was then incubated at $4^{\circ} \mathrm{C}$ for $24 \mathrm{~h}$ and centrifuged. The supernatant included the soluble $\mathrm{A} \beta_{1-42}$ preparation; the major species was $\mathrm{A} \beta_{1-42}$ monomer and also included the trimer, tetramer, and, to a lesser extent, the dimer [19]. Scrambled $\mathrm{A} \beta_{1-42}$ peptide was prepared in the same manner as $\mathrm{A} \beta_{1-42}$. GAS was dissolved in $0.9 \%$ sterile saline to deserved concentrations.

2.3. Single Unit Recordings. A five-barrel glass microelectrode (total tip diameter 3-10 $\mu \mathrm{m}$, resistance 5-20 M 2 ) was used for electrophysiological recording and micropressure injection. The recording glass microelectrode was filled with a $0.9 \%$ sodium chloride solution. The other four barrels connected with a 4-channel pressure injector (PM2000B, Micro Data Instrument, Inc., USA) and were filled with different drugs as needed. The drugs were ejected on the surface of the firing cells with gas pressure [20]. The intrabarrel drugs' concentrations were chosen based on previous established works $[8,21,22]$ and their efficacy to reliably alter neuronal firing. $0.5 \mu \mathrm{L}$ of drug was applied to the firing neurons during injection. The signals from the recording electrode were fed to an AM system amplifier (Carlsborg, WA, USA) and filtered with a band-pass of $0.3-10 \mathrm{kHz}$. A single unit was isolated and analyzed using Spike 2 (Cambridge Electronic Design Limited, London, UK). The signal was stored in a computer equipped with MATLAB analysis system for further offline analysis. The unit activities were subsequently analyzed per $500 \mathrm{~s}$ epoch for averaging discharge rates (bin width, $10 \mathrm{~s}$ ), which were normalized relative to $500 \mathrm{~s}$ baseline values. To avoid the transient effects of the injection, windows of analysis were started $500 \mathrm{~s}$ after the injection of the drugs of interest.

2.4. Whole-Cell Patch Clamp Recordings. Sprague-Dawley rats (P12-21) were used in this study. After halothane anesthesia, each animal was decapitated and the brain was removed quickly. The brain was subsequently submerged in cold ACSF containing (in mM) $125 \mathrm{NaCl}, 2.5 \mathrm{KCl}, 25 \mathrm{NaHCO}_{3}, 1.25$ $\mathrm{KH}_{2} \mathrm{PO}_{4}, 1.2 \mathrm{MgSO}_{4}, 2 \mathrm{CaCl}_{2}$, and 10 dextrose, bubbled with $95 \% \mathrm{O}_{2}-5 \% \mathrm{CO}_{2}$, with a $\mathrm{pH}$ of 7.4 . The brain was blocked, and an oscillating tissue slicer (Leica, VT1000, Wetzlar, Germany) was used to cut $400 \mu \mathrm{m}$ thick horizontal sections with a slicing angle of $20^{\circ}$. Slices were initially incubated for a minimum of $90 \mathrm{~min}$ at room temperature $\left(22-24^{\circ} \mathrm{C}\right)$ in ACSF and were then transferred to and submerged in a 
recording chamber where they were perfused continuously with carbogen buffered ACSF at room temperature. Wholecell patch clamp recordings were obtained from cell bodies of EC stellate neurons. Data acquisition was conducted with EPC10 amplifiers (HEKA Elektronik, Lambrecht/Pfalz, Germany). The signal was stored for offline analysis with Pulse/Pulse fit v.8.74 (HEKA Elektronik) and Igor Pro v.4.03 (WaveMatrics). Pipettes (4-8 $\mathrm{M} \Omega$ ) for whole-cell recordings were pulled on a horizontal micropipette puller (P-97, Sutter Instrument) from filamented capillary glass and were filled with a pipette solution containing (in $\mathrm{mM}$ ) $145 \mathrm{~K}$-gluconate, 0.5 EGTA, $2 \mathrm{MgCl}_{2}$, 5 HEPES, 5 K-ATP, 0.4 Na-GTP, pH 7.4, and 290-295 mOsm. Liquid junction potential was calculated to be approximately $-10 \mathrm{mV}$ for the internal solutions, and membrane voltages were corrected offline. Series resistance was compensated by $80 \%$ and was continually monitored throughout the experiment. Neurons were discarded if the series resistance changed by more than $15 \%$.

2.5. Data Analysis. Statistical analysis was made using statistical analysis software Origin 8.0 (Microcal, Inc, Northampton, MA, USA) and SPSS 18.0 (IBM, New York, NY). The values were presented as the mean \pm S.E.M. Differences in the mean values among groups were analyzed using Student's $t$-test and one-way ANOVA. Values of $P<0.05$ were considered significant.

\section{Results}

3.1. Soluble $A \beta_{1-42}$ Increased the Spontaneous Firing Activities of EC Neurons. The changes in activity of EC neurons were determined by the spontaneous discharge before and after the application of soluble $\mathrm{A} \beta_{1-42}$. Figure 2(a) shows a typical recording of unit activity from a single neuron. All of the spikes recorded in the present study showed a biphasic positive/negative waveform. A spike-sorting technique was used to separate single neuronal activity. Based on the different amplitudes and waveforms of spikes, recorded activities were sorted by principal components analysis (PCA). Figure 2(b) shows representative sampling of waveforms from one EC neuron over $1800 \mathrm{~s}$. Under basal conditions, the waveforms were stable, indicating that all of the recorded spikes were indeed from a single neuron. Figure 2(c) presents offline classification of spikes with PCA. It is obvious that PCA analysis revealed one data cluster in the PCA-feature space, further indicating that all of the spikes recorded were from one neuron.

Previous electrophysiological results elucidated that $\mathrm{A} \beta_{1-42}$ could excite hippocampal neurons in vitro [9]. In the following experiment, we further investigated the effects of soluble $\mathrm{A} \beta_{1-42}$ on the activities of $\mathrm{EC}$ neurons in anesthetized rats in vivo. Representative illustrations of firing changes in EC neurons after the application of vehicle or soluble $\mathrm{A} \beta_{1-42}$ are shown in Figure 3(a). The administration of $200 \mu \mathrm{M}$ $\mathrm{A} \beta_{1-42}$ increased the firing rates of EC neurons with an onset time about 300-900 s. As is shown in Figure 3(b), potentiation of the mean firing rate built up over the first $1000 \mathrm{~s}$ following the injection of $\mathrm{A} \beta_{1-42}$, stable for $500 \mathrm{~s}$.
Then, the mean firing rate gradually returned to baseline values, indicating that the effects of soluble $A \beta_{1-42}$ on the discharge of EC neurons were reversible. At $1000 \mathrm{~s}$ after injection of $\mathrm{A} \beta_{1-42}$, the mean firing rate was $323.4 \pm 47.9 \%$ of the baseline values (Figure 3(b), $n=11, P<0.01$ versus baseline (500 s before injection)). In contrast, the vehicle group, as a control, had no obvious effect on the firing activities of EC neurons (Figure 3(b), $n=11, P>0.05$ versus baseline). The mean firing rate of vehicle group at $1000 \mathrm{~s}$ after injection was $99.0 \pm 24.5 \%$ of baseline, which was significantly different from that of the $\mathrm{A} \beta_{1-42}$ group (Figure 3(c), $n=11$ for each group, $P<0.01$ ). To ensure that the increase in discharge induced by $\mathrm{A} \beta_{1-42}$ was not due to nonspecific peptide effects, we applied a scrambled $\mathrm{A} \beta_{1-42}$ peptide to EC neurons. As shown in Figures 3(a)-3(c), the scrambled $A \beta_{1-42}$ peptide did not have significant effect on the mean firing rate of EC neurons. The average firing rate of scrambled $\mathrm{A} \beta_{1-42}$ group at $1000 \mathrm{~s}$ after injection was $107.3 \pm 26.0 \%$, which was not significantly different from that of the vehicle group (Figure $3(\mathrm{c}), n=6$ for scrambled $\mathrm{A} \beta_{1-42}$ group, $P>0.05)$. Altogether, these findings suggest that soluble $A \beta_{1-42}$, but not its scrambled form, can significantly increase the spontaneous discharge of EC neurons.

As shown in Figure 3(d), we further analyzed the correlation between $\mathrm{A} \beta_{1-42}$-induced excitation at $1000 \mathrm{~s}$ after injection and the basal firing rate in the 11 neurons. Although modest, there was a negative correlation $(r=-0.59, P<0.05)$ between these two parameters, suggesting that the neurons with slower basal firing rate are more affected by $\mathrm{A} \beta_{1-42}$ in the EC.

3.2. GAS Prevented Soluble $A \beta_{1-42}$-Induced Increase in Firing Activity. We then tested whether GAS can inhibit the soluble $\mathrm{A} \beta_{1-42}$-induced perturbation of spontaneous discharge. Both saline (used as a control) and $10 \mathrm{mM}$ GAS alone had no obvious effect on the firing activities of EC neurons during the experiment (Figure 4(a)). The mean firing rates at $1000 \mathrm{~s}$ after application of the saline or $10 \mathrm{mM}$ GAS were $101.7 \pm$ $27.6 \%(n=6, P>0.05$ versus baseline $)$ and $98.1 \pm 27.4 \%$ ( $n=6, P>0.05$ versus baseline), respectively (Figures $4(\mathrm{~b})$ and $4(\mathrm{c}))$. The administration of $200 \mu \mathrm{M} \mathrm{A} \beta_{1-42}$ increased the spontaneous discharge of EC neurons (Figure 4(a)). At $1000 \mathrm{~s}$ after injection of $\mathrm{A} \beta_{1-42}$, the mean firing rate was $333.6 \pm 39.9 \%$ of the baseline values (Figures $4(\mathrm{~b})$ and $4(\mathrm{c}$ ), $n=10, P<0.01$ versus baseline). Applying $10 \mathrm{mM}$ GAS to EC neurons significantly suppressed the $A \beta_{1-42}$-induced increase in firing activity (Figure $4(a)$ ). The firing rate at $2000 \mathrm{~s}$ after $\mathrm{A} \beta_{1-42}$ application (equal to that at $1000 \mathrm{~s}$ after GAS application) was $98.3 \pm 32.3 \%$ of the baseline values, which was significantly less than that of $A \beta_{1-42}$ alone group at the time point (Figures 4(b) and 4(c), $219.9 \pm 44.9 \%, n=11$ for $\mathrm{A} \beta_{1-42}$ alone group, $\left.P<0.05\right)$.

To further investigate the relationship between concentration and inhibitory effects of GAS, we pretreated the recorded EC neurons with different concentrations of GAS before $A \beta_{1-42}$ injection. A representative illustration of the firing changes in EC neurons pretreated with GAS alone is shown in Figure 5(a). Saline or 10 mM GAS was applied when 


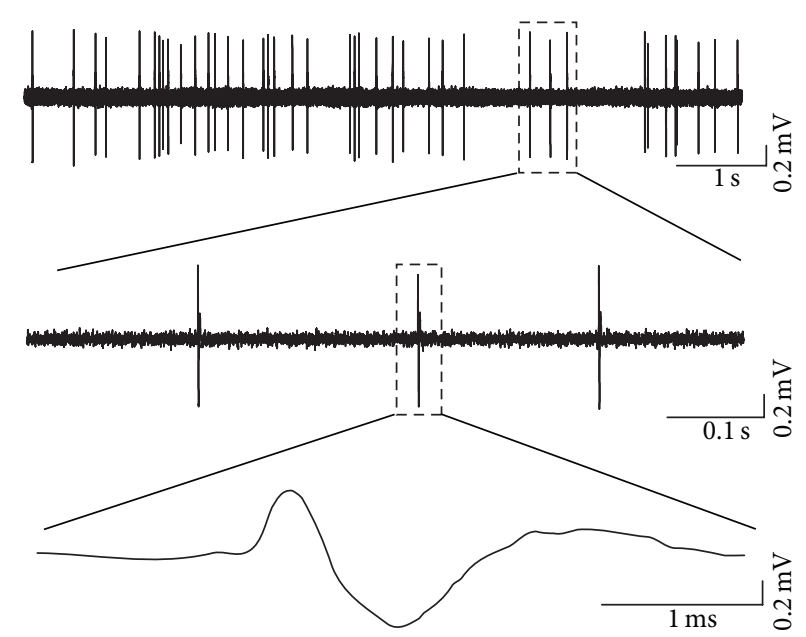

(a)

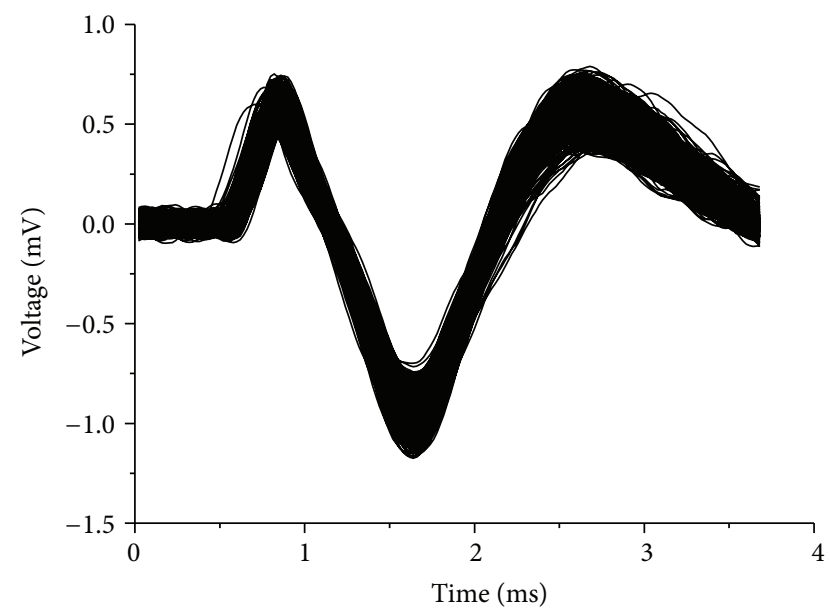

(b)

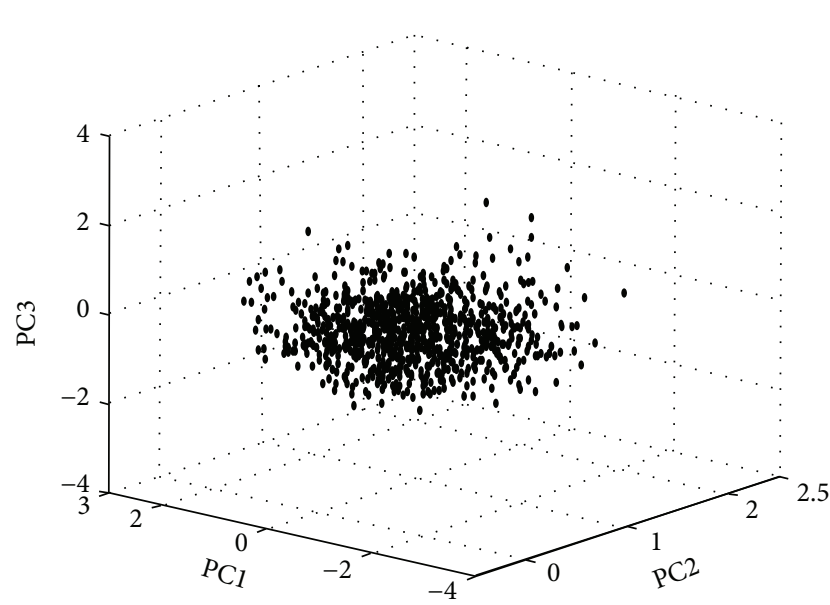

(c)

FIGURE 2: Recording and sorting of spontaneous discharge of EC neurons. (a) Single unit spontaneous discharge recorded in EC neurons (upper). The lower two panels are the enlargements of the indicated regions in the upper panel. (b) The overdrawn waveforms of firing events during a $30 \mathrm{~min}$ period form one cluster, indicating that all of the spikes were from one neuron. (c) Offline classification of spikes with principle component analysis (PCA). Every spike shown in (b) is projected onto the PCA-feature space shown in (c), further indicating that all of the spikes were from one neuron.

the spontaneous discharge was stable for $500 \mathrm{~s}$. As shown in Figures 5(a) and 5(b), the administration of $200 \mu \mathrm{M} \mathrm{A} \beta_{1-42}$ increased the firing rate of $\mathrm{EC}$ neurons pretreated with saline. At $1000 \mathrm{~s}$ after injection of $\mathrm{A} \beta_{1-42}$ (equal to that at $1500 \mathrm{~s}$ after saline application), the mean firing rate was $309.4 \pm$ $38.3 \%$ of the baseline values (Figure 5(b), $n=6, P<0.01$ versus baseline). In contrast, following pretreatment with $10 \mathrm{mM}$ GAS, no obvious increase in the firing activities in EC neurons was detected after the application of $200 \mu \mathrm{M} \mathrm{A} \beta_{1-42}$ (Figures 5(a) and 5(b), $113.1 \pm 28.4 \%, n=6, P>0.05$ versus baseline). Analysis of the firing rates at $1000 \mathrm{~s}$ after application of $\mathrm{A} \beta_{1-42}$ (equal to that at $1500 \mathrm{~s}$ after pretreatment with different concentrations of GAS) revealed that the inhibitory effects of GAS against $\mathrm{A} \beta_{1-42}$ were concentration-dependent (Figure 5(c), saline alone group: $97.8 \pm 24.5 \%$, saline plus $\mathrm{A} \beta_{1-42}$ group: $309.4 \pm 38.3 \%, 100 \mu \mathrm{M}$ GAS plus $\mathrm{A} \beta_{1-42}$ group: $216.9 \pm 36.3 \%, 1 \mathrm{mM}$ GAS plus $\mathrm{A} \beta_{1-42}$ group: $166.0 \pm 30.5 \%$, and $10 \mathrm{mM}$ GAS plus $\mathrm{A} \beta_{1-42}$ group: $113.1 \pm 28.4 \%, n=6$ for each group, ${ }^{\#} P<0.05,{ }^{\#} P<0.01$ versus saline alone group, ${ }^{\&} P<0.05,{ }^{\& \&} P<0.01$ versus saline plus $\mathrm{A} \beta_{1-42}$ group, $\left.{ }^{*} P<0.05,{ }^{* *} P<0.01\right)$. These results indicated that GAS had protective effects against the abnormal, $A \beta_{1-42}$-induced activities of EC neurons.

3.3. GAS Blocked $A \beta_{1-42}$-Elicited Inward Currents in EC Neurons. To explore the cellular mechanisms underlying the protective effects of GAS on $\mathrm{A} \beta_{1-42}$-induced perturbation of neuronal activity, we analyzed the effects of GAS on the excitability of soluble $A \beta_{1-42}$-treated EC neurons in an in vitro slice preparation. As stellate neurons are the most abundant EC neurons [23], we took recordings from 8 randomly selected EC stellate neurons in current-clamp mode. Consistent with the in vivo results (Figure 3 ), bath application 

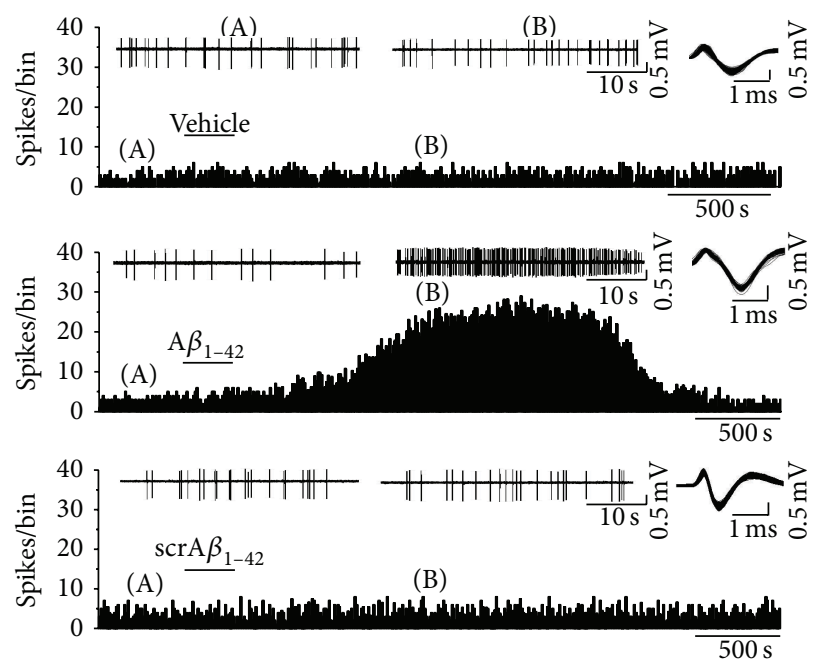

(a)

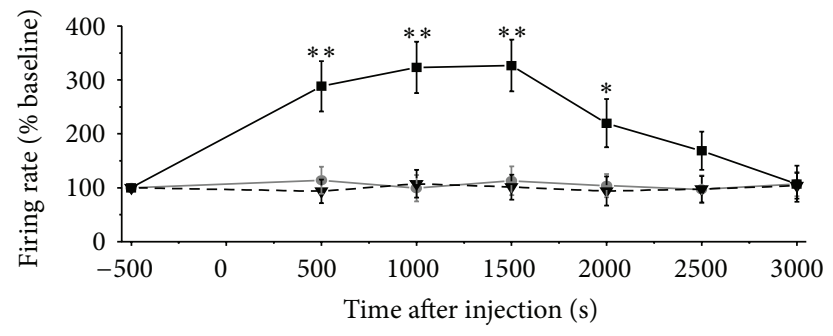

$$
\begin{aligned}
& \text {-•- Vehicle } \\
& \text {-- } \mathrm{A} \beta_{1-42} \\
& \text {-- } \mathrm{scrA} \beta_{1-42}
\end{aligned}
$$

(b)

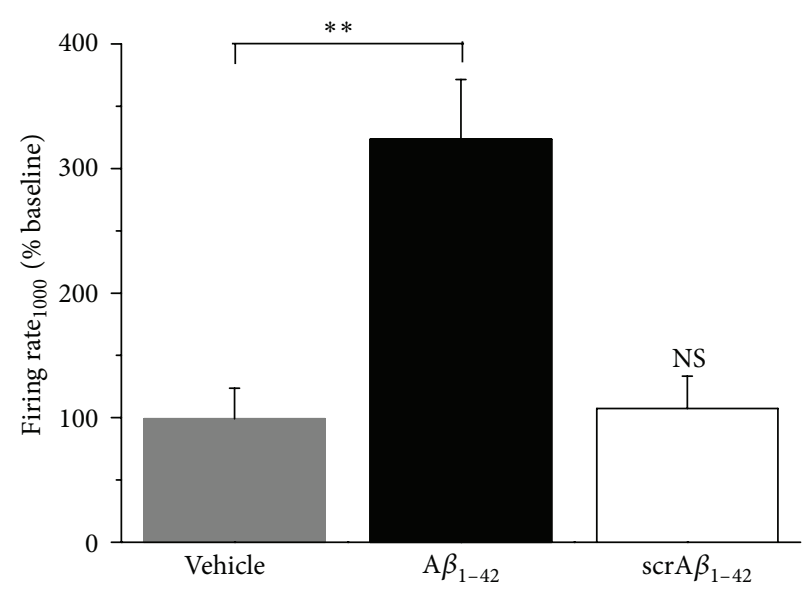

(c)

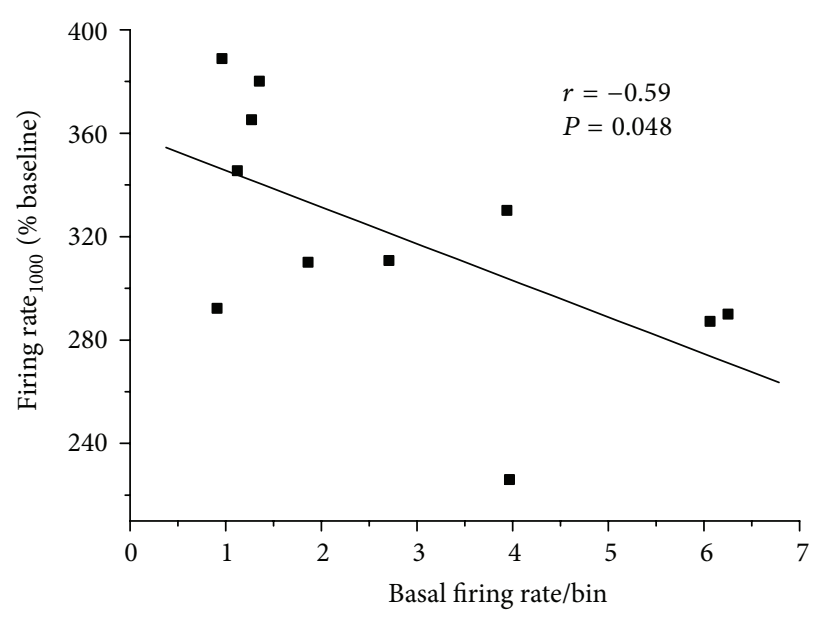

(d)

FIGURE 3: Effects of $\mathrm{A} \beta_{1-42}$ on the spontaneous firing of EC neurons. (a) Representative traces show the changes of firing activity of EC neurons after application of vehicle (upper), $\mathrm{A} \beta_{1-42}$ (middle), and scrambled $\mathrm{A} \beta_{1-42}$ (lower). Drugs were applied during the bar. The two traces in upper panel show firing patterns before (A) and after (B) the application of drugs. The upper right panel of each group displays the waveform of the recorded neuron across each protocol. No obvious change in the spike shape parameters was observed. (b) Time-response curves of the firing rate changes in EC neurons after administration of vehicle, $\mathrm{A} \beta_{1-42}$, and scrambled $\mathrm{A} \beta_{1-42}\left({ }^{*} P<0.05\right.$, ${ }^{* *} P<0.01$ versus baseline values (500 s before injection)). (c) Bar graph summarizing effects of vehicle, $\mathrm{A} \beta_{1-42}$, and scrambled $\mathrm{A} \beta_{1-42}$ on the firing rate of EC neurons at $1000 \mathrm{~s}$ after local injection $\left({ }^{* *} P<0.01\right.$, NS, no significant difference versus vehicle group). (d) Correlation between the firing rate at $1000 \mathrm{~s}$ after injection and the basal firing values in EC neurons. A $\beta_{1-42}$ tended to enhance the low-rate spontaneous discharge more strongly. 

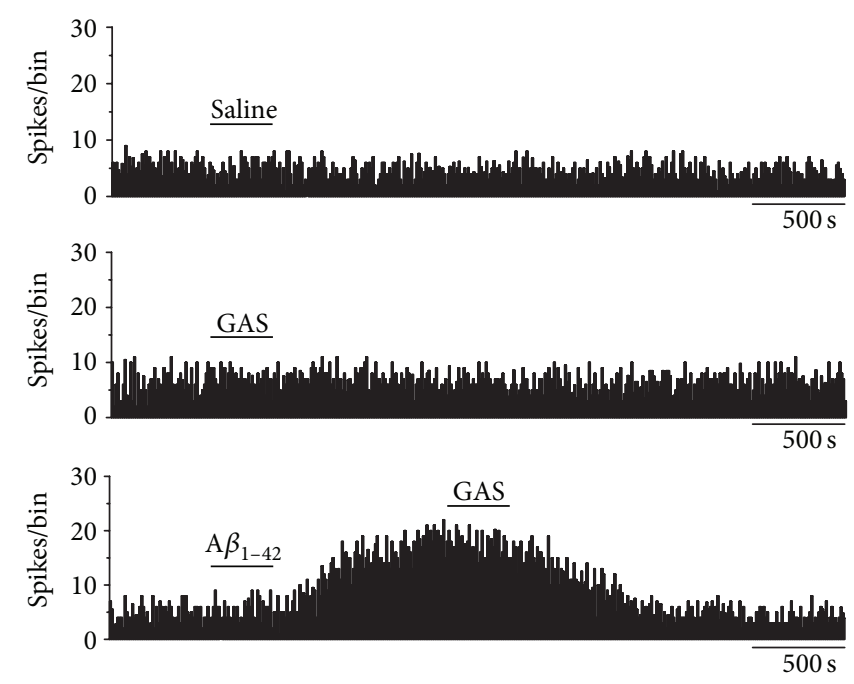

(a)

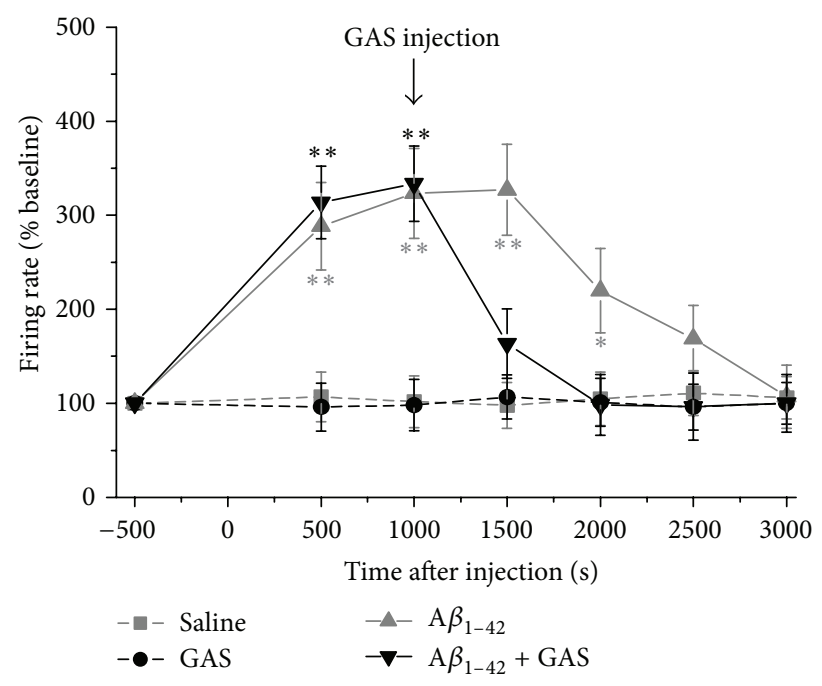

(b)

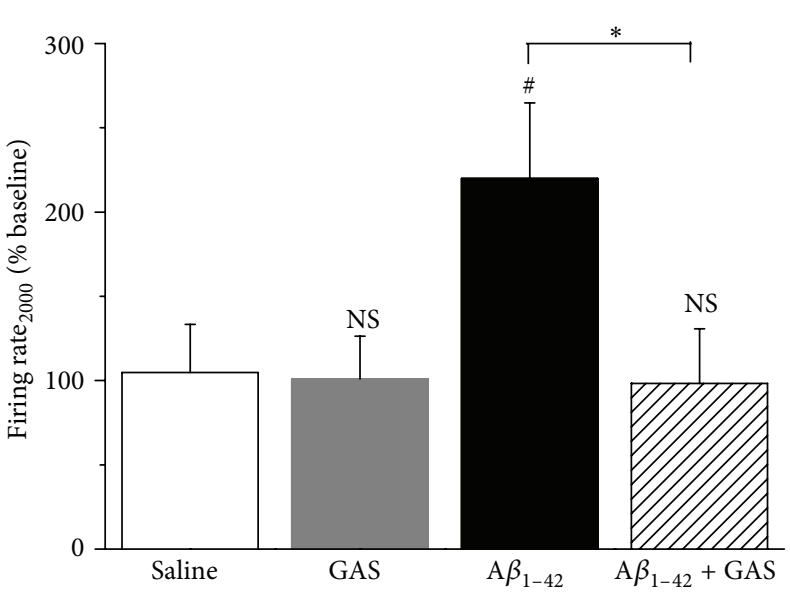

(c)

FIGURE 4: Inhibitory effects of GAS on $\mathrm{A} \beta_{1-42}$-induced increase in spontaneous discharge in EC region. (a) Representative traces of firing rate of EC neurons after the application of saline (upper), GAS alone (middle), or A $\beta_{1-42}$ plus GAS (lower). Saline or GAS alone did not exert any obvious effect on the firing activities. Application of the GAS decreased the spontaneous discharge of A $\beta_{1-42}$-induced hyperexcitation. (b) Time-response curves for saline, GAS alone, $\mathrm{A} \beta_{1-42}$ alone, and $\mathrm{A} \beta_{1-42}$ plus GAS groups on the firing rates of EC neurons $\left(^{*} P<0.05\right.$, ${ }^{* *} P<0.01$ versus baseline values). (c) Histograms showing the mean discharge rate of EC neurons in different groups at $2000 \mathrm{~s}$ after injection (NS, no significant difference versus vehicle group, ${ }^{\#} P<0.05$ versus saline group, ${ }^{*} P<0.05$ ).

of $300 \mathrm{nM} \mathrm{A} \beta_{1-42}$ significantly increased the excitability of all recorded EC neurons (Figure 6(a)). Meanwhile, the robust $\mathrm{A} \beta_{1-42}$-induced firing of EC neurons was gradually diminished and completely abolished by the coapplication of $100 \mu \mathrm{M}$ GAS (Figures 6(a) and 6(b)). We next examined the effects of $\mathrm{A} \beta_{1-42}$ and GAS on whole-cell currents of EC neurons. In voltage-clamp mode, the recorded EC neurons were held at $-70 \mathrm{mV}$. A brief (100 s) application of $300 \mathrm{nM}$ $\mathrm{A} \beta_{1-42}$ elicited stable inward currents in the majority of the neurons (6/8). Intriguingly, administration of GAS significantly blocked the $\mathrm{A} \beta_{1-42}$-elicited inward currents in a dosedependent manner (Figures 6(c) and 6(d)). The amplitude of $\mathrm{A} \beta_{1-42}$-elicited inward currents gradually decreased as the dose of GAS increased from $10 \mu \mathrm{M}$ to $100 \mu \mathrm{M}$ (Figure $6(\mathrm{~d}$ ), $\mathrm{A} \beta_{1-42}$ alone group: $40.1 \pm 5.4 \mathrm{pA}, 10 \mu \mathrm{M}$ GAS plus $\mathrm{A} \beta_{1-42}$ group: $32.3 \pm 3.4 \mathrm{pA}, 50 \mu \mathrm{M}$ GAS plus $\mathrm{A} \beta_{1-42}$ group: $16.2 \pm$ $2.6 \mathrm{pA}$, and $100 \mu \mathrm{M}$ GAS plus $\mathrm{A} \beta_{1-42}$ group: $8.0 \pm 2.3 \mathrm{pA}$, $n=6$ for each group, ${ }^{\#} P<0.05,{ }^{\#} P<0.01$ versus $\mathrm{A} \beta_{1-42}$ alone group, $\left.{ }^{*} P<0.05,{ }^{* *} P<0.01\right)$. Altogether, these results suggest that GAS inhibits $\mathrm{A} \beta_{1-42}$-induced hyperactivity by blocking $\mathrm{A} \beta_{1-42}$-elicited inward currents in EC neurons.

\section{Discussion}

In the present study, we used extracellular single unit recording techniques to investigate the action of soluble $\mathrm{A} \beta_{1-42}$ 


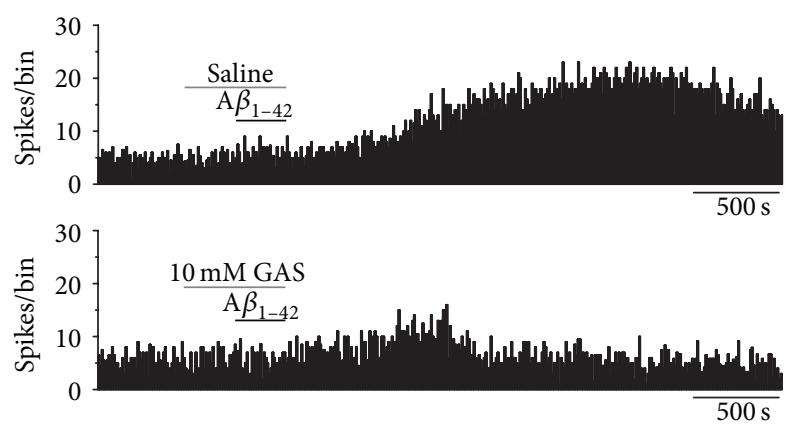

(a)

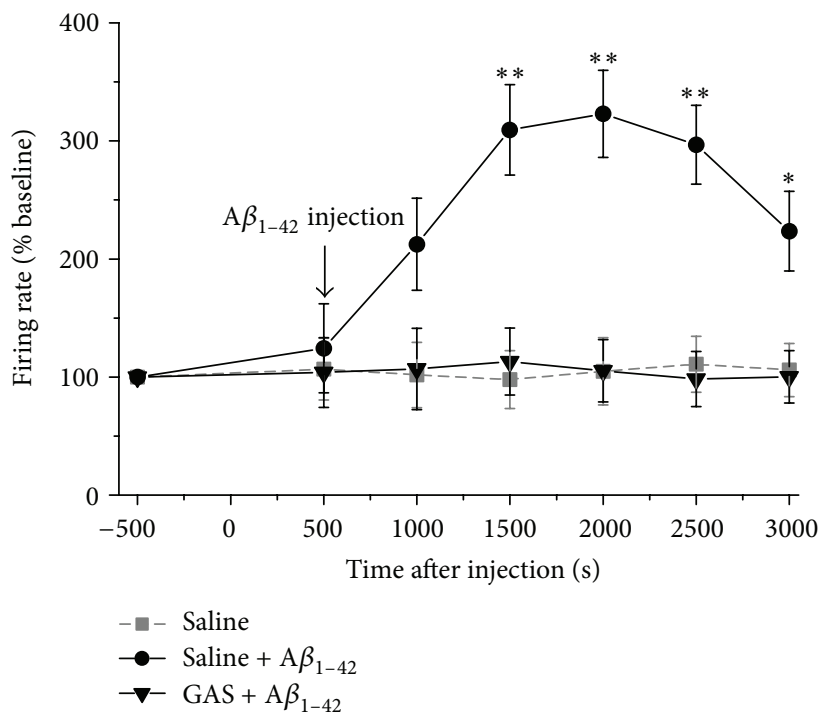

(b)

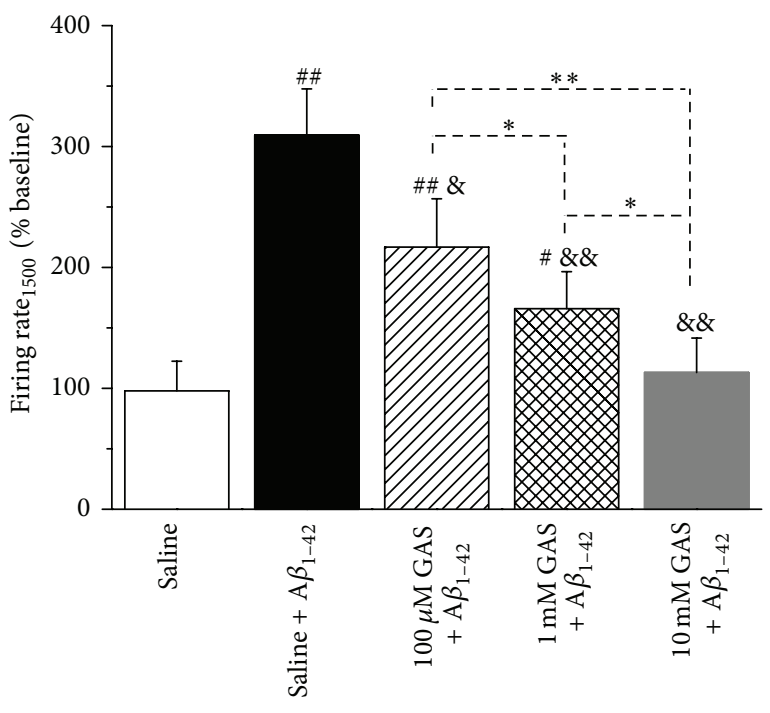

(c)

FIgURE 5: GAS pretreatment inhibited $A \beta_{1-42}$-induced increase in firing rate of EC neurons in a concentration-dependent manner. (a) Representative traces show that pretreatment with $10 \mathrm{mM}$ GAS (lower) prevented the $\mathrm{A} \beta_{1-42}$-induced increase in firing rate of EC neurons, whereas saline (upper) had no obvious effect. (b) Time-response curves of $\mathrm{A} \beta_{1-42}$-induced changes of firing rate in EC neurons, pretreated with saline or $10 \mathrm{mM} \mathrm{GAS}\left({ }^{*} \mathrm{P}<0.05,{ }^{* *} \mathrm{P}<0.01\right.$ versus baseline values ( $500 \mathrm{~s}$ before saline or GAS injection)). (c) Concentration-dependent inhibitory effects of GAS on $\mathrm{A} \beta_{1-42}$-induced firing rate changes $\left({ }^{\#} P<0.05,{ }^{\#} P<0.01\right.$ versus saline alone group, ${ }^{\text {\& }} P<0.05$, ${ }^{\& \&} P<0.01$ versus saline plus $\mathrm{A} \beta_{1-42}$ group, $\left.{ }^{*} P<0.05,{ }^{* *} P<0.01\right)$.

on EC neuronal discharge in vivo. Our results demonstrated that local application of soluble $\mathrm{A} \beta_{1-42}$ significantly increased neuronal spontaneous discharge in the EC region (Figure 3 ). GAS prevented the alteration of the spontaneous discharge of EC neurons induced by $\mathrm{A} \beta_{1-42}$ (Figures 4 and 5). Wholecell patch clamp results showed GAS blocked $A \beta_{1-42}$-elicited inward currents of EC neurons (Figure 6).

4.1. GAS May Have Potential Therapeutic Value for A $\beta$ Induced Aberrant Activity. The EC occupies a central position in the limbic forebrain by providing bidirectional interconnections between the hippocampal formation and the rest of the cerebral cortex [4]. Animal experimentations and clinical observations in humans have demonstrated that the EC-hippocampal-neocortical circuit is fundamental in some forms of memory [4]. Some aspects of memory impairments in $\mathrm{AD}$ patients have been attributed to the damage of
EC [24], which is one of the earliest and most severely damaged brain areas in this disease [5]. In the present in vivo study, we provided electrophysiological evidence that direct application of soluble $\mathrm{A} \beta_{1-42}$ could increase the spontaneous discharge of EC neurons (Figure 3). The production of $A \beta$ and its secretion into the extracellular space are tightly regulated by neuronal activity. Increased neuronal activity enhances $\mathrm{A} \beta$ production, whereas blocking neuronal activity has the opposite effect [25]. We suspect that $A \beta$-induced hyperactivity of EC neurons can increase the production of $\mathrm{A} \beta$, raising the possibility of a vicious cycle in which $\mathrm{A} \beta$ promotes its own production through alterations of $\mathrm{EC}$ neuronal activity. This vicious cycle may further impair the integrity and functions of neurons in the EC-hippocampal circuit, as $\mathrm{A} \beta$ synthesized by EC neurons can be transported via the perforant pathway to the hippocampus [3]. Thus, early interference in the EC to break this vicious cycle might be of therapeutic benefits, perhaps halting disease progression. 


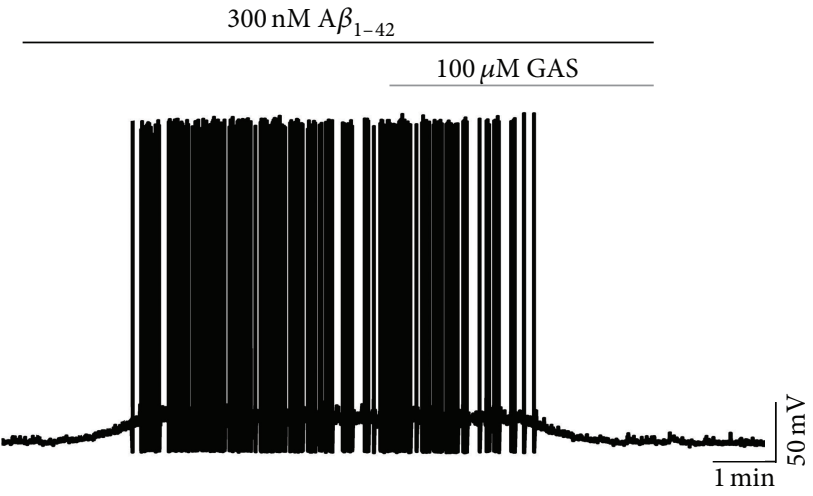

(a)

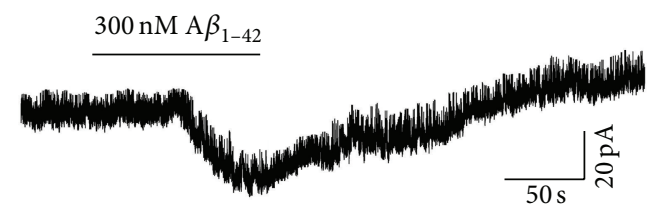

$100 \mu \mathrm{M}$ GAS

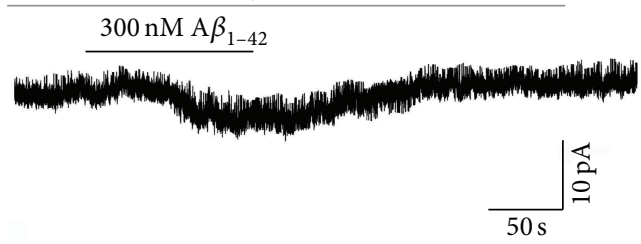

(c)

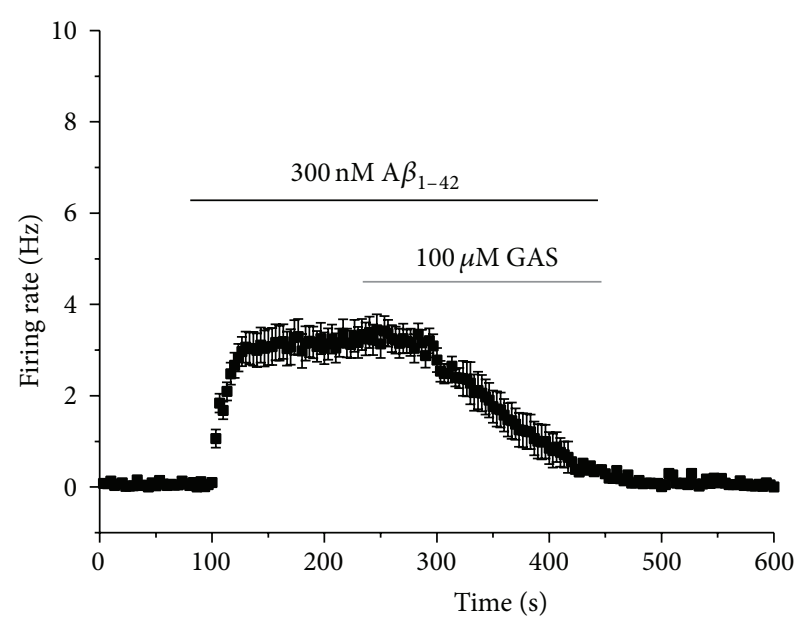

(b)

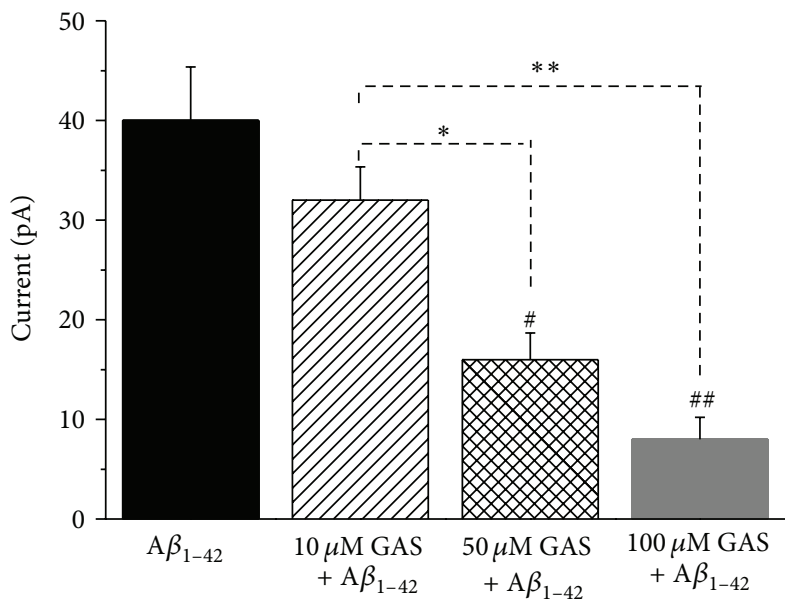

(d)

FIGURE 6: Inhibitory effects of GAS on $\mathrm{A} \beta_{1-42}$-elicited inward currents in EC neurons. (a) $\mathrm{A} \beta_{1-42}$-induced neuronal hyperexcitation was significantly inhibited in the presence of GAS. (b) Group data of 8 tested EC neurons showing the A $\beta_{1-42}$-induced changes in the firing rate calculated at $5 \mathrm{~s}$ intervals. (c) $300 \mathrm{nM} \mathrm{A} \beta_{1-42}$ elicits inward currents in an EC neuron. GAS blocked the A $\beta_{1-42}$-induced inward currents. (d) Group data of 6 tested EC neurons. The pretreatment of GAS decreased A $\beta_{1-42}$-elicited inward currents in a dose-dependent manner ( ${ }^{\#} P<0.05,{ }^{\# \#} P<0.01$ versus $\mathrm{A} \beta_{1-42}$ alone group, ${ }^{*} P<0.05,{ }^{* *} P<0.01$ ).

The ancient Chinese herb Gastrodia elata is considered to have several beneficial effects in treating headaches, dizziness, tetanus, and epilepsy $[12,13,26,27]$. Importantly, GAS, the main active component of Gastrodia elata, can penetrate through the blood-brain barrier into the brain [13]. A recent study suggests that GAS protects primary cultured rat hippocampal neurons against $\mathrm{A} \beta$-induced neurotoxicity, alleviating memory deficits and reducing neuropathology in a mouse model of $\mathrm{AD}$ [17]. These findings suggested that GAS might be effective in AD. The present study showed that administration of GAS reversed the $\mathrm{A} \beta_{1-42}$-induced spontaneous discharge alteration of EC neurons (Figure 4) and that this inhibitory effect of GAS was dose-dependent (Figure 5). In contrast, the same dose of GAS alone did not affect the firing activity of EC neurons (Figure 4). These results indicate that GAS may selectively act on spontaneous activity in abnormal $\mathrm{A} \beta$ states. We infer from the above results that
GAS may be a beneficial agent in relieving the aberrant EChippocampal network activity in $\mathrm{AD}$ progression.

\subsection{Potential Ionic Mechanisms Underlying the Protective} Effects of GAS against A $\beta$-Induced Aberrant Activity. To explore the cellular mechanisms underlying the protective effects of GAS against $\mathrm{A} \beta_{1-42}$-induced aberrant activity, we used an in vitro slice preparation to perform whole-cell patch clamp recordings in EC neurons. Soluble $\mathrm{A} \beta_{1-42}$ caused a membrane depolarization and discharge in rat EC neurons (Figure 6(a)). These findings are consistent with the observation that direct application of soluble $\mathrm{A} \beta_{1-42}$ can induce EC neuronal hyperactivity in vivo (Figure 3 ). Furthermore, we found that $\mathrm{A} \beta_{1-42}$ elicited inward currents in EC neurons (Figure 6(b)). It has been reported that intracellularly or extracellularly applied $\mathrm{A} \beta$ or its fragments can modulate 
the function of ion channels, including potassium $\left(\mathrm{K}^{+}\right)$, calcium $\left(\mathrm{Ca}^{2+}\right)$, and sodium $\left(\mathrm{Na}^{+}\right)$channels [28]. In wildtype mice, $\mathrm{A} \beta_{1-42}$ decreases a suite of $\mathrm{K}^{+}$conductance, including the delayed rectifier, the transient A-type, and the $\mathrm{Ca}^{2+}$-activated $\mathrm{K}^{+}$currents [28].

In the present study, we found that the effects of $A \beta_{1-42}$ were almost completely prevented by treatment with GAS (Figures 6(c) and 6(d)). A possible interpretation of the present findings is that GAS may exert its beneficial effects partially through the regulation of $\mathrm{Na}^{+}$or $\mathrm{K}^{+}$currents. Previous study has shown that GAS can dose-dependently reverse the pathologically altered $\mathrm{Na}^{+}$and $\mathrm{K}^{+}$currents in small dorsal root ganglion neurons in a model of diabetes [29]. In addition, GAS may also exert its beneficial effects through modulating $\mathrm{Ca}^{2+}$ currents. It has been shown that GAS can prevent glutamate-induced $\mathrm{Ca}^{2+}$ influx [30]. In contrast, $\mathrm{A} \beta$ enhances excitatory activity in glutamatergic synaptic networks and causes $\mathrm{Ca}^{2+}$ influx [31]. We infer that this opposing regulation of $\mathrm{Ca}^{2+}$ influx may contribute to the beneficial effects of GAS on the $\mathrm{A} \beta_{1-42}$-evoked abnormal excitability of EC neurons. It should be noted that ionic currents may not be the only target for GAS, and the effects of GAS on other cellular targets and signaling pathways cannot be excluded.

In summary, the current study showed that GAS treatment ameliorated $\mathrm{A} \beta_{1-42}$-induced perturbation of EC neuronal activity. These results suggested that GAS may be a potential candidate for $\mathrm{AD}$ therapy.

\section{Conflict of Interests}

The authors declare that there is no conflict of interests regarding the publication of this paper.

\section{Acknowledgments}

This work was supported by Grants from the National Natural Foundation of China (31100759), the Scientific Foundation of Chongqing (CSTC2011BB5039), and the High Education Teaching Reform Project of Chongqing (no. 132080) to Dr. Zhi-ru Zhu. The authors also acknowledge the support by a grant from the Natural Sciences and Engineering Research Council of Canada (NSERC discovery grant) to Dr. Fenglian $\mathrm{Xu}$.

\section{References}

[1] C. Lee, G. H. Park, S.-R. Lee, and J.-H. Jang, "Attenuation of $\beta$-amyloid-induced oxidative cell death by sulforaphane via activation of NF-E2-related factor 2," Oxidative Medicine and Cellular Longevity, vol. 2013, Article ID 313510, 12 pages, 2013.

[2] J. J. Palop and L. Mucke, "Epilepsy and cognitive impairments in Alzheimer disease," Archives of Neurology, vol. 66, no. 4, pp. 435-440, 2009.

[3] J. A. Harris, N. Devidze, L. Verret et al., "Transsynaptic progression of amyloid- $\beta$-induced neuronal dysfunction within the entorhinal-hippocampal network," Neuron, vol. 68, no. 3, pp. 428-441, 2010.
[4] H. Eichenbaum and P. A. Lipton, "Towards a functional organization of the medial temporal lobe memory system: role of the parahippocampal and medial entorhinal cortical areas," Hippocampus, vol. 18, no. 12, pp. 1314-1324, 2008.

[5] T. Gómez-Isla, J. L. Price, D. W. McKeel Jr., J. C. Morris, J. H. Growdon, and B. T. Hyman, "Profound loss of layer II entorhinal cortex neurons occurs in very mild Alzheimer's disease," Journal of Neuroscience, vol. 16, no. 14, pp. 4491-4500, 1996.

[6] A. T. Du, N. Schuff, D. Amend et al., "Magnetic resonance imaging of the entorhinal cortex and hippocampus in mild cognitive impairment and Alzheimer's disease," Journal of Neurology Neurosurgery and Psychiatry, vol. 71, no. 4, pp. 441447, 2001.

[7] U. A. Khan, L. Liu, F. A. Provenzano et al., "Molecular drivers and cortical spread of lateral entorhinal cortex dysfunction in preclinical Alzheimer's disease," Nature Neuroscience, vol. 17, no. 2, pp. 304-311, 2014.

[8] S. H. Yun, G. Gamkrelidze, W. B. Stine et al., "Amyloidbetal-42 reduces neuronal excitability in mouse dentate gyrus," Neuroscience Letters, vol. 403, no. 1-2, pp. 162-165, 2006.

[9] S. C. Ren, P. Z. Chen, H. H. Jiang et al., "Persistent sodium currents contribute to Abeta-induced hyperexcitation of hippocampal CA1 pyramidal neurons," Neuroscience Letters, vol. 580C, pp. 62-67, 2014.

[10] Y. Wang, G. Zhang, H. Zhou, A. Barakat, and H. Querfurth, "Opposite effects of low and high doses of $\mathrm{A} \beta 42$ on electrical network and neuronal excitability in the rat prefrontal cortex," PLoS ONE, vol. 4, no. 12, Article ID e8366, 2009.

[11] Y.-F. Pan, X.-T. Jia, X.-H. Wang et al., "Arginine vasopressin remolds the spontaneous discharges disturbed by amyloid $\beta$ protein in hippocampal CA1 region of rats," Regulatory Peptides, vol. 183, no. 1, pp. 7-12, 2013.

[12] W. Tang and G. Eisenbrand, "Gastrodia elata Bl," in Chinese Drugs of Plant Origin, pp. 545-548, Springer, Berlin, Germany, 1992.

[13] L. M. Ojemann, W. L. Nelson, D. S. Shin, A. O. Rowe, and R. A. Buchanan, "Tian ma, an ancient Chinese herb, offers new options for the treatment of epilepsy and other conditions," Epilepsy and Behavior, vol. 8, no. 2, pp. 376-383, 2006.

[14] Z. Zhang, P. Ma, Y. Xu et al., "Preventive effect of gastrodin on cognitive decline after cardiac surgery with cardiopulmonary bypass: a double-blind, randomized controlled study," Journal of Huazhong University of Science and Technology (Medical Science), vol. 31, no. 1, pp. 120-127, 2011.

[15] Z.-H. Liu, H.-T. Hu, G.-F. Feng, Z.-Y. Zhao, and N.-Y. Mao, "Protective effects of gastrodin on the cellular model of Alzheimer's disease induced by A $\beta 25-35$," Sichuan Da Xue Xue Bao Yi Xue Ban, vol. 36, no. 4, pp. 537-540, 2005.

[16] M.-T. Hsieh, C.-R. Wu, and C.-F. Chen, "Gastrodin and phydroxybenzyl alcohol facilitate memory consolidation and retrieval, but not acquisition, on the passive avoidance task in rats," Journal of Ethnopharmacology, vol. 56, no. 1, pp. 45-54, 1997.

[17] X. Zhao, Y. Zou, H. Xu et al., "Gastrodin protect primary cultured rat hippocampal neurons against amyloid-beta peptide-induced neurotoxicity via ERK1/2-Nrf2 pathway," Brain Research, vol. 1482, pp. 13-21, 2012.

[18] X. Chen, Y. Guo, J. Feng et al., "Encoding and retrieval of artificial visuoauditory memory traces in the auditory cortex requires the entorhinal cortex," Journal of Neuroscience, vol. 33, no. 24, pp. 9963-9974, 2013. 
[19] M. P. Lambert, K. L. Viola, B. A. Chromy et al., "Vaccination with soluble $\mathrm{A} \beta$ oligomers generates toxicity-neutralizing antibodies," Journal of Neurochemistry, vol. 79, no. 3, pp. 595-605, 2001.

[20] J. H. Jhamandas, R. W. Lind, and L. P. Renaud, "Angiotensin II may mediate excitatory neurotransmission from the subfornical organ to the hypothalamic supraoptic nucleus: an anatomical and electrophysiological study in the rat," Brain Research, vol. 487, no. 1, pp. 52-61, 1989.

[21] V. Szegedi, G. Juhász, D. Budai, and B. Penke, "Divergent effects of $A \beta 1-42$ on ionotropic glutamate receptor-mediated responses in CA1 neurons in vivo," Brain Research, vol. 1062, no. 1-2, pp. 120-126, 2005.

[22] G. Orbán, K. Völgyi, G. Juhász et al., "Different electrophysiological actions of 24- and 72-hour aggregated amyloidbeta oligomers on hippocampal field population spike in both anesthetized and awake rats," Brain Research, vol. 1354, pp. 227$235,2010$.

[23] A. Alonso and R. Klink, "Differential electroresponsiveness of stellate and pyramidal-like cells of medial entorhinal cortex layer II," Journal of Neurophysiology, vol. 70, no. 1, pp. 128-143, 1993.

[24] W. Wu and S. A. Small, "Imaging the earliest stages of Alzheimer's disease," Current Alzheimer Research, vol. 3, no. 5, pp. 529-539, 2006.

[25] J. J. Palop and L. Mucke, "Amyloid-B-induced neuronal dysfunction in Alzheimer's disease: from synapses toward neural networks," Nature Neuroscience, vol. 13, no. 7, pp. 812-818, 2010.

[26] J. Xu and S. Guo, "Retrospect on the research of the cultivation of Gastrodia elata $\mathrm{Bl}$, a rare traditional Chinese medicine," Chinese Medical Journal, vol. 113, no. 8, pp. 686-692, 2000.

[27] M. Spinella, "Herbal medicines and epilepsy: the potential for benefit and adverse effects," Epilepsy and Behavior, vol. 2, no. 6, pp. 524-532, 2001.

[28] K. Alier, L. Ma, J. Yang, D. Westaway, and J. H. Jhamandas, "A $\beta$ inhibition of ionic conductance in mouse basal forebrain neurons is dependent upon the cellular prion protein PrP C," Journal of Neuroscience, vol. 31, no. 45, pp. 16292-16297, 2011.

[29] W. Sun, B. Miao, X.-C. Wang et al., "Gastrodin inhibits allodynia and hyperalgesia in painful diabetic neuropathy rats by decreasing excitability of nociceptive primary sensory neurons," PLoS ONE, vol. 7, no. 6, Article ID e39647, 2012.

[30] G. Jiang, H. Wu, Y. Hu, J. Li, and Q. Li, "Gastrodin inhibits glutamate-induced apoptosis of pc12 cells via inhibition of CaMKII/ASK-1/p38 MAPK/p53 signaling cascade," Cellular and Molecular Neurobiology, vol. 34, no. 4, pp. 591-602, 2014.

[31] L. Texidó, M. Martín-Satué, E. Alberdi, C. Solsona, and C. Matute, "Amyloid $\beta$ peptide oligomers directly activate NMDA receptors," Cell Calcium, vol. 49, no. 3, pp. 184-190, 2011. 

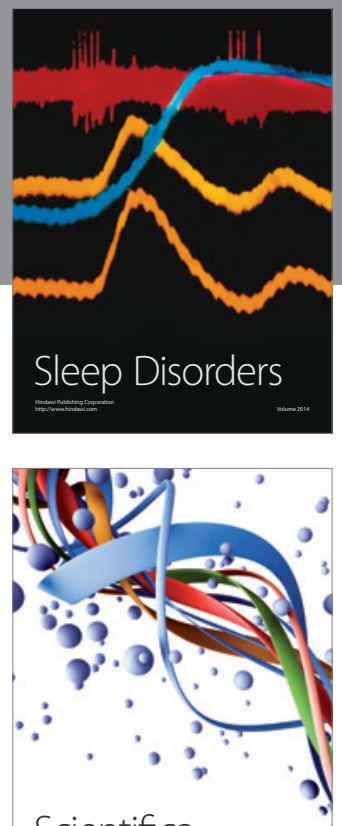

Scientifica
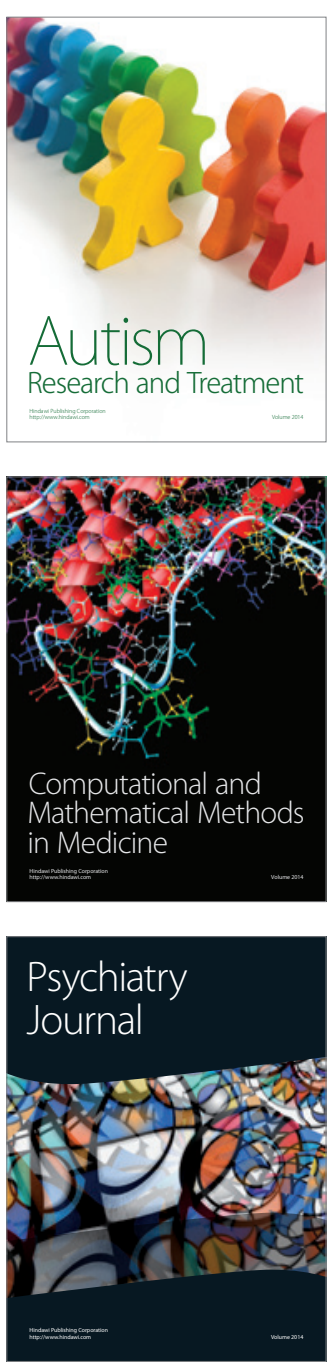
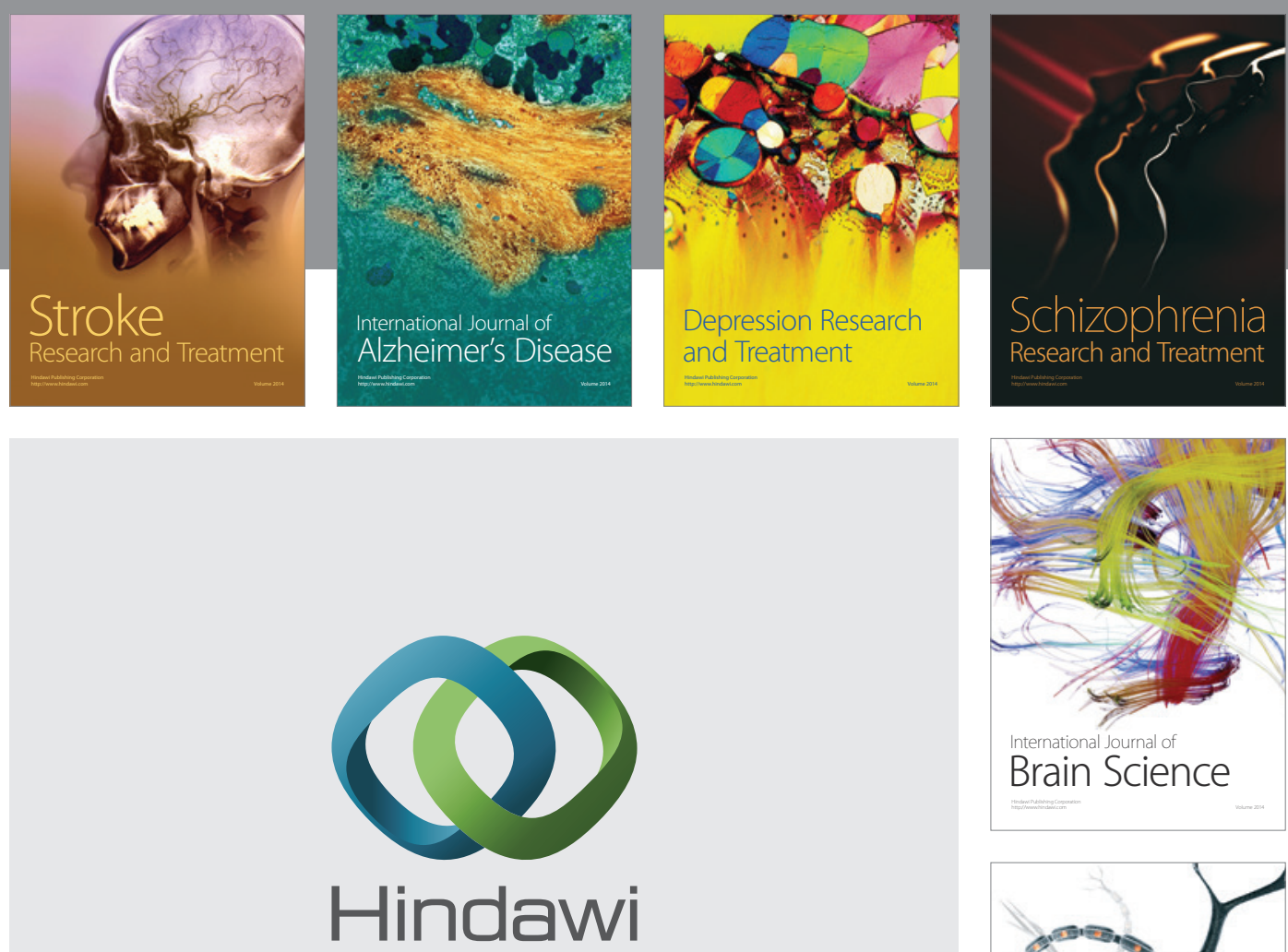

Submit your manuscripts at

http://www.hindawi.com
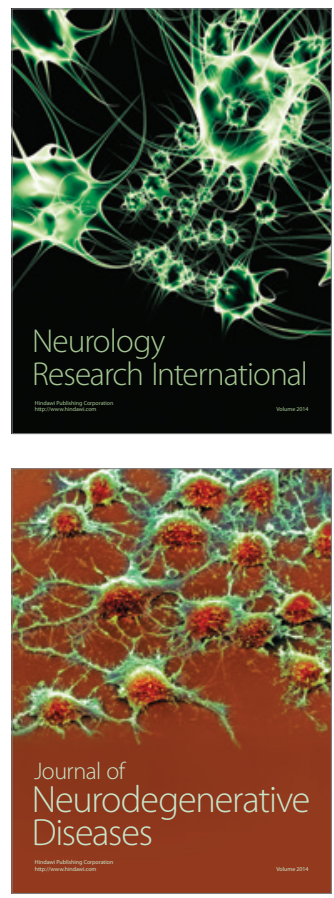

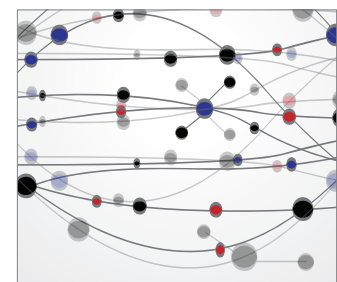

The Scientific World Journal
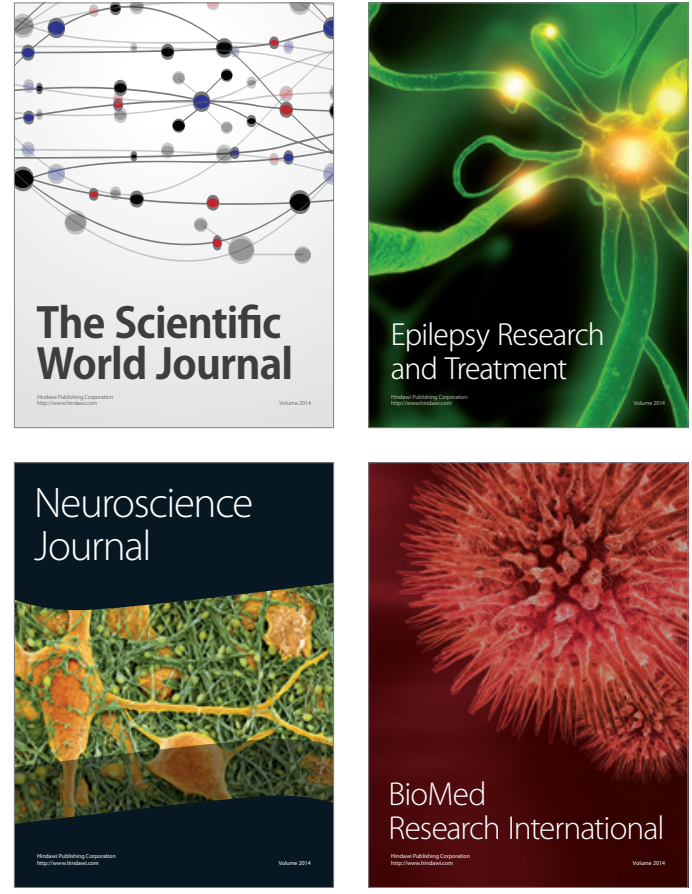

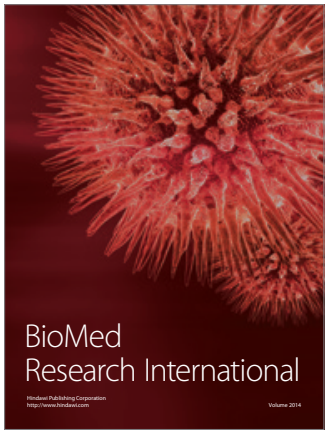

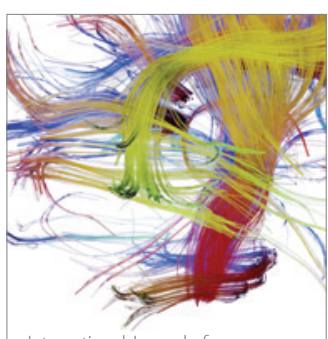

Brain Science

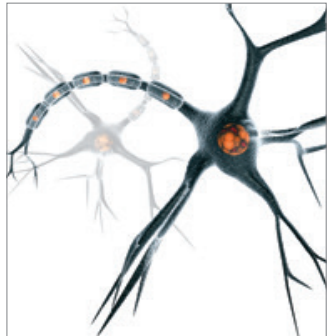

Neural Plasticity
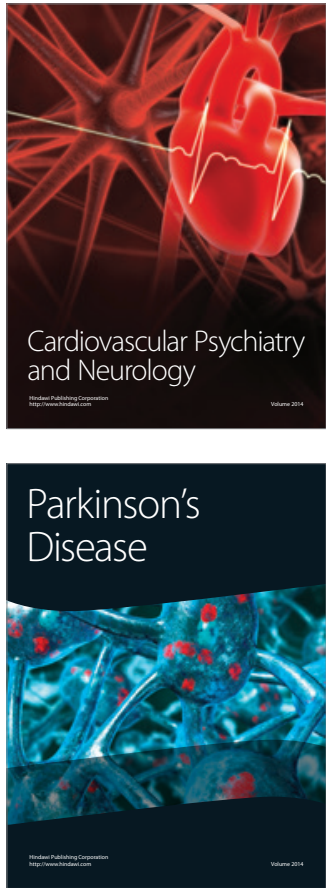